\title{
«Постойная повинность есть, конечно, одна из самых тягостных для граждан». Постойная повинность и строительство казарм в Российской империи второй половины XIX века
}

\author{
А.С. Орлов \\ Академия федеральной службы охраны Российской Федерации, \\ Россия, 302015, г. Орел, ул. Приборостроительная, 35 \\ E-mail: Orlov-orl@mail.ru
}

\begin{abstract}
Аннотация. В данной статье на основе анализа повременных изданий Российской империи второй половины XIX века рассматривается вопрос преобразования постойной повинности и строительства казарм для русской армии. Постой являлся одним из наиболее тяжелых налогов (наиболее тяжелым бременем) для податных сословий. Во второй половине XIX века правительство Российской империи прилагало усилия для облегчения отбывания данной повинности простым населением. Строилось незначительное количество специальных помещений для войск. В период «великих реформ» императора Александра II работала комиссия для пересмотра системы податей и сборов. Однако комиссия не смогла кардинальным образом изменить систему отбывания постоя и освободить податные сословия от отбывания повинности натуральным образом. С 1882 года в Российской империи началось активное строительство казарменных помещений для армии. И в результате этого к началу XX века правительство полностью перевело армию на казарменное положение, тем самым освободив податные сословия от постойной повинности.
\end{abstract}

Ключевые слова: Александр II, военная реформа, «Московские Ведомости», «Голос», «Биржевые Ведомости», «Новое Время», «Гражданин», «Отечественные записки».

Для цитирования: Орлов А.С. 2020. «Постойная повинность есть, конечно, одна из самых тягостных для граждан». Постойная повинность и строительство казарм в Российской империи второй половины XIX века. Via in tempore. История. Политология, 47 (4): 811-817. DOI: $10.18413 / 2687-0967-2020-47-4-811-817$.

\section{«Free quarter is definitely one of the heaviest duties for citizens». Free quarter and barracks building in the Russian Empire of the second half of the XIX century}

\author{
Andrey S. Orlov \\ Russian Federation Security Guard Service Federal Academy, \\ 35 Priborostroitel'naya St., Orel, 302015, Russia \\ E-mail: Orlov-orl@mail.ru
}

\begin{abstract}
The article analyzes the transformation of free quarter duty and the issue of building barracks for the Russian army through Russian publications of the second half of the XIX century. Free quarter was definitely one of the heaviest obligations for all groups of citizens. In the second half of the XIX century the government of the Russian Empire attempted to relieve common people of this burden. Special facilities for the army were built then, but there weren't many of them. During the "great reforms» of Emperor Alexander II there worked a committee on revision of the system of duties and obligations. But it failed to significantly change free quarter system and relieve citizens of physical duties. However, starting from 1881 the Russian Empire began to actively build barracks for the army. As result,
\end{abstract}


by the beginning of the XX century the government managed to accommodate all army forces in barracks, thus entirely relieving the citizens of free quarter duty.

Keywords: Alexander II, military reform, «Moskovskie Vedomosti», «Golos», «Birzhevye Vedomosti», «Novoe Vremya», «Grazhdanin», «Otechestvennye zapiski».

For citation: Orlov A.S. 2020. «Free quarter is definitely one of the heaviest duties for citizens». Free quarter and barracks building in the Russian empire of the second haif of the XIX century. Via in tempore. History and political science, 47 (4): 811-817 (in Russian). DOI: 10.18413/2687-0967-2020-474-811-817.

\section{Введение}

60-70-е годы XIX века ознаменованы либеральными преобразованиями Александра II. В Российской империи происходил ряд крупных реформ, затрагивающих все сферы жизнедеятельности государства. После проигранной Крымской войны (1853-1856 гг.) стала очевидной необходимость коренных изменений в армии. В 1861 году на должность военного министра был назначен профессор Николаевской академии генерального штаба граф Д.А. Милютин, на которого и была возложена обязанность провести данные преобразования. В период проведения военной реформы сокращался количественный состав армии, открывались новые учебные заведения, расширялась подготовка кадров, территория страны была поделена на 15 военных округов, совершенствовалась система военного управления, армия перевооружалась по новому образцу, была введена всеобщая воинская повинность и пересмотрены сроки службы в армии. В период преобразований военному министру пришлось решать множество проблем. Одной из них являлась потребность в размещении войск в казармах и в пересмотре постойной повинности для населения [Зайончковский, 1952, с. 46]. Изменения, которые происходили в военном ведомстве, также влияли и на развитие Российского государства, в частности на эволюцию постойной повинности, которая играла большую роль во взаимоотношениях гражданского и военного населения Российской империи.

Постойная повинность или расквартирование войск по квартирам (домам) городских и сельских жителей явилась для государства наиболее дешевой формой содержания армии. Эта повинность носила натуральный характер, изначально была безденежной и являлась одной из самых тяжелых (наряду с рекрутской повинностью) из тех, что должно было нести податное сословие России. Данная проблема являлась одной из самых острых в течение XVIII-XIX веков. Квартирная повинность серьезно искажала социокультурное, социально-бытовое и демографическое развитие российского общества [Яковлева Л.Е., 2008, c. 3].

\section{Объект и методы исследования}

Методология исследования проблемы развития постойной повинности в Российской империи во второй половине XIX века автором основана на основополагающих принципах исторического познания: принципе историзма, объективности и системности. В процессе подготовки материалов статьи использовались методы компаративистского, хронологического анализа, а также метод статистики.

\section{Результаты исследования}

Вопрос о необходимости строительства казарм и размещения в них войск возник вместе с созданием регулярной армии Петром I. Однако в связи с достаточно напряженной военно-политической обстановкой размещение войск в казармах было затруднительным. Российской армии на протяжении XVIII века регулярно приходилось воевать и от- 
стаивать внешнеполитические интересы страны, и она не могла иметь мест постоянной дислокации. К тому же государство постоянно стремилось сократить расходы на военную сферу, например, обязав простое население размещать у себя в домах солдат и офицеров без какой-либо платы. Военнослужащим в отсутствии учений и лагерных сборов приходилось располагаться в домах у городского и сельского населения, которое, помимо того, что должно было принимать у себя совершенно чужих людей, обязывалось еще и обеспечивать проживающих солдат и офицеров дровами, свечами, постельными принадлежностями и продовольствием. Наиболее обременительным военный постой был для простого мужика. «Прежде, в старину, когда, по слухам, и урожаи были обильнее и повинности собирались не в таком изобилии, как нынче, - мужики, говорят, были рады принять и угостить служилого человека» [Отечественные записки, 1870, № 2]. Но с увеличением налогового гнета у крестьянина стало меньше возможностей кормить за свой счет солдат, находящихся у него на постое. Поэтому приходилось мужику скрываться в собственном доме и принимать пищу тайком от солдат, дабы не кормить их. А плохо накормленный солдат становился зол и неуслужлив к хозяину дома и старался навредить ему.

В 1711 году создается квартирмейстерская служба, которая и занималась непосредственным размещением войск на постое. В 1716 году Воинский устав впервые подробно разъяснил систему размещения армии по квартирам. Изменения правовых норм, правил размещения войск в столицах и крупных городах империи подтолкнули власти к концу XVII столетия к строительству казарм. Еще при императоре Петре I предпринимались попытки устроить полковые слободы; при Екатерине II пытались устроить казармы для целых полков [Новое Время, 1875, № 244]. Источником финансирования были определены городские обыватели, в том числе и путем принуждения [Яковлева Л.Е., 2008, с. 3]. С этого времени государство стало больше внимания уделять постройке казарм.

В первой половине XIX века правительство стало понимать тяжесть постойной повинности для населения и стало предпринимать попытки реформирования данной системы. Но практически все проекты были отложены на неопределенный срок из-за отсутствия денег у государства, а также из-за тех войн, которые вела Российская империя.

Также в данный период утвердились две новые системы уравнивания военного постоя - это строительство казарм и выдача военнослужащим квартирных денег. Так, в первой половине XIX века произошли большие изменения в постойной повинности. К этому времени, по сравнению с XVIII веком, было построено большое количество казарменныХ помещений за государственный счет и частью за счет городских сумм в СанктПетербурге, Москве, Вильно и некоторых других городах, жители которых были полностью освобождены от военного постоя. В результате действий государства к третьей четверти XIX века казармы были построены только в 202 городах и местечках, и в них располагалось 209000 генералов, штаб- и обер-офицеров и нижних чинов, т. е. 1/3 часть русской армии, а остальные 550000 человек по-прежнему располагались в квартирах обывателей по городам и селам, причем на долю последних приходилось $1 / 3$ часть [Новое Время, 1875, № 244].

Со второй половины XIX века регулирование расквартирования армии осуществлялось по положениям Устава о земских повинностях, который был издан в 1851 году. Пятая глава устава полностью регламентировала вопросы расквартирования войск [Свод законов Российской империи, 1857, Устав о земских повинностях, с. 67-120]. Однако на практике устав 1851 года имел много неточностей и недочетов. В результате чего податные сословия теперь должны были не только предоставлять войскам свои квартиры, но и сдавать определенную сумму денег на строительство инфраструктуры для войск. Также устав должен был способствовать равномерному распределению расквартировываемых войск среди населения. Но этого достичь так и не удалось. Таким образом, данный документ требовал во многом пересмотра и уточнения. 
После проигранной Крымской войны и с началом либеральных преобразований Александра II началась деятельность Комиссии для пересмотра системы податей и сборов. Надо отметить, что военные преобразования нашей армии во второй половине XIX века органически вписываются в военные преобразования стран Европы, таких как Пруссия (которая являлась своеобразной «законодательницей мод» в вопросах реформирования армии), Англия, Франция, Австрия. Проводить данные преобразования было крайней необходимостью для Российской империи, так как наша страна в XVIII и XIX веках превратилась в «жандарма Европы» и без ее ведома не происходил ни один военный конфликт в Европе. Так, газета «Голос» в 1870 году отмечала, что военные преобразования в период царствования Александра II вдохнули в армию новую жизнь, и она стала сопоставима с лучшими европейскими армиями, однако для того чтобы эти изменения вошли «в плоть и кровь армии», нужно дать вооруженным силам «возможность организовываться согласно предпочтениям законодателя». Но это возможно лишь тогда, когда войска имеют такие же хорошие бытовые условия в казармах, как в Европе [Голос, 1870, № 357].

Таким образом, реорганизации военного постоя стали уделять еще больше внимания, что не могло не остаться незамеченным повременными изданиями того времени. На страницах таких газет и журналов, как «Голос», «Новое Время», «Московские ведомости», «Неделя», «Гражданин», «Биржевые ведомости», «Молва», «Отечественные записки», стали появляться статьи, посвященные данному вопросу.

Тяжесть отбывания постойной повинности для населения отмечалась российскими повременными изданиями. Так, «Отечественные записки» утверждали, что «должно признать вполне справедливым, что постойная натуральная повинность является совершенно отжившей свой век и служит препятствием к дальнейшему совершенствованию армии, а также и к нормальному развитию благосостояния народа, который нуждается в этом преобразовании едва ли не более всех» [Отечественные записки, 1866, № 2, с. 148].

Как мы уже сказали выше, постой в натуральном виде существовал отчасти и в тех городах, где жители согласились заменить его денежным сбором, но там это натуральный постой выражался в возмущающей форме: к домовладельцу, не уплатившему причитающегося с него сбора. Квартирная комиссия посылает на постой одного из офицеров до тех пор, пока домовладелец не внесет причитающихся с него денег; затем тот же офицер посылается к другому неисправному домовладельцу для вынуждения и этого к уплате [Голос, 1869, № 264].

Еще одним немаловажным отрицательным аспектом в постойной повинности, который не обошли своим вниманием повременные издания, являлась смертность в войсках от тесноты в казармах и их непригодности для проживания по медицинским показаниям. Устав 1851 года определял размер отводимых помещений. Так, «в комнату длиной в 4, а шириной от 3 до 4 сажень ставить 16 человек нижних чинов, а в комнаты длиной 3 и шириной в 3 сажени - по 10 человек, а в меньшие - по 6 человек» [Свод законов Российской империи, 1857, Устав о земских повинностях, с. 67-120]. Но очень часто случалось так, что, для того чтобы освободиться от постоя, хозяин дома предоставлял отдельное помещение, непригодное для проживания: «...не соответствующие своему назначению, часто старые конюшни. Фабрики, склады, которые нет возможности приспособить ни для обучения в них значительных частей, ни для помещения людей» [Московские ведомости, 1871, № 183].

Поэтому у населения, подлежащего призыву в армию, интересующегося бытовыми условиями, да и у самих солдат возникал инстинктивный страх перед казармой. Так, согласно исследованиям военного доктора Столярова в его статье о казарменных помещениях нашей армии, одной из причин большого количества заболеваний в среде военнослужащих является санитарное состояние казарм. По исследованиям академика Буняковского, смертность гражданского населения была меньше, чем в армии.

Приведем данные из исследования доктора Столярова, подтверждающие наши слова [Московские ведомости, 1871, № 183; Биржевые Ведомости, 1871. № 180]: 


\begin{tabular}{|l|c|c|c|c|c|}
\hline & В казармах & На квартире в городе & В деревнях & В лагере & Вообще \\
\hline Заболело & 548 & 500 & 300 & 346 & 543 \\
\hline Умерло & 20 & 13 & 8 & 1,5 & 12 \\
\hline
\end{tabular}

Из данных сведений видно, что при расположении войск в казармах, не удовлетворяющих санитарным требованиям, смертность оказывалась выше, чем в деревнях и лагерях. Основной причиной болезней являлось отсутствие необходимого количества воздуха в помещении на одного человека. Так, к примеру, в странах Европы, в частности в Англии, на человека приходилось 600 кубических футов воздуха, во Франции, Пруссии, Австрии - около 500, а в России - от 343 до 515,5 кубических футов, тогда как на брюссельском конгрессе 1858 года было определено, что количество воздуха на каждого солдата должно быть не менее 715 кубических футов [Московские ведомости, 1871, № 183]. Таким же образом для того, чтобы устранить причины смертности в войсках, нужно было, по мнению доктора Столярова, строить казармы, удовлетворяющие гигиеническим правилам. Но решение данного вопроса в 60-е и 70-е годы XIX века было отложено практически до 1882 года. Лишь с 1882 года начался активный этап строительства казарменных помещений. Однако, как указывала газета «Гражданин», вопрос о санитарном состоянии казарменных помещений так и не был до конца решен. Прежде всего необходимо было сделать общеобязательным условие, чтобы помещения строились вдали от фабрик и заводов, имели бы «покои светлые, сухие и теплые», чтобы в них не было питейных заведений, трактиров, ресторанов. Площадь данных помещений должна была обеспечивать 1 кубический сажень воздуха на одного человека [Гражданин, 1889, № 56]. Но во многих домах, отводимых в провинциальных городах под казармы, эти требования не соблюдались.

Газеты «Голос» и «Московские Ведомости» сходились во мнении, что только грамотный, обученный солдат способен понять те новые требования, которые предъявляет к нему новый род его деятельности. Однако это было невозможно, во-первых, без сокращения срока обязательной службы, а во-вторых, без размещения войск в казармах, где бы они проживали и обучались военному делу весь год, а не только четыре месяца в году, во время лагерных сборов. Такая подготовка солдата была возможна только при казарменном размещении [Голос, 1869, № 259; Московские ведомости, 1869, №№ 209 и 210]. Но, несмотря на все предпринимаемые действия по строительству казарм, почти до конца XIX века практиковалась натуральная постойная повинность. Казармы строили земства, города, сельские общества [Московские ведомости, 1869, № 281; Неделя, 1880, № 13; Новое Время, 1875, №№ 1153 и 1179; Молва, 1879, № 197], в результате чего к началу $\mathrm{XX}$ века почти $94 \%$ всей армии было размещено в специальных воинских помещениях [Яковлева Л.Е., 2008, с. 126].

Однако существовали противники строительства казарм. Так, по сообщениям газеты «Голос», «наши скептики в деле казарм приводят против них следующий довод: солдат вырабатывается из мужика; мужик смолоду привык жить на чистом воздухе, а в казармах воздух спертый; солдату, ввиду сохранения здоровья, полезнее жить 8 месяцев в году в деревне, чем в казармах... Солдат на обывательской квартире не получает так называемых приварочных денег, а получает довольствие с крестьянского стола» [Голос, 1869, № 259].

\section{Заключение}

Таким образом, начиная с конца 1882 года весь казарменный капитал, образованный из денежных сборов за отбывание постойной повинности, был передан в Военное министерство. Тогда же было начато активное возведение специальных помещений для войск. Такое решение стало основой для успешной реализации данного вопроса. Так, к 1892 году было построено уже казарм для 117 воинских частей. Масштабы строительства постоянно возрастали, и в результате к 1 января 1900 года в военном ведомстве было воз- 
ведено 19015 казарменных помещений. Примерно 94 \% всей армии было размещено в специальных помещениях.

В таких условиях Российской империи пришлось полностью отказаться от расквартирования армии методом постоя у простого населения и предпринять усилия для строительства казарм в наиболее важных стратегических направлениях.

При этом проявились определенные тенденции в совершенствовании управления военным контингентом. К ним можно отнести:

1. Обеспечение российской армии казарменными помещениями дало возможность поднять уровень военного обучения простого солдата, а также значительно сократить сроки мобилизации армии в случае военной опасности, что стало важным критерием боеготовности.

2. Размещение в местах постоянной дислокации воинских подразделений дало возможность командирам и начальникам усилить контроль за дисциплиной военнослужащих и поднять на более высокий уровень систему воинского воспитания.

Переосмысление проблем расквартирования армии во второй половине XIX века привело к преобразованиям в сфере постойной повинности. Постепенно натуральная постойная повинность исчезла. И к началу XX века правительство полностью перевело войска на казарменное расположение.

\section{Список источников}

1. Внутренняя хроника. 1875. Новое время, 1153. 16 мая: 2.

2. Внутренняя хроника. 1875. Новое время, 1179. 13 июня: 2.

3. Внутренняя хроника. 1875. Новое Время, 244. 10 декабря: 2.

4. Еще о постойной повинности. 1869. Голос, 264. 24 сентября (6 октября): 1.

5. Казарменный вопрос. 1879. Молва, 197. 20 июля: 1.

6. Казармы. 1869. Московские Ведомости, 209. 24 сентября: 617-619.

7. Казармы. 1869. Московские ведомости, 281. 24 декабря: 829-832.

8. Казармы и военные преобразования нынешнего времени. 1870. Голос, 357. 28 декабря (9 января): 1.

9. Наши общественные дела. 1870. Отечественные записки, 2: 358.

10. Неудовлетворительность казарменных помещений нашей армии. 1871. Московские ведомости, 183. 21 августа: 551.

11. Обзор специальных журналов. 1866. Отечественные записки, 2: 148.

12. По вопросу о постоянных казармах для размножения войск. 1871. Биржевые Ведомости, 180. 4 июля: 2.

13. Потребности в учительских семинариях в Виленском округе. 1869. Московские Ведомости, 210. 25 сентября: 619-621.

14. Потребности войск и земства. 1889. Гражданин, 56. 25 февраля: 1.

15. Правила о выдаче земствам ссуд на постройку казарм. 1880. Неделя, 13. 30 марта: 399.

16. Расквартирование войск и постойная повинность. 1869. Голос, 259. 19 октября: 1.

17. Свод законов Российской Империи. Т. 4. Кн. 2. Устав о земских повинностях. СПб., Гос. Типография, 1857.

\section{Список литературы}

1. Зайончковский П.А. 1952. Военные реформы 1860-1870 гг. в России. М., Изд-во Московского ун-та, 46.

2. Яковлева Л.Е. 2008. Развитие постойной повинности в России в XVIII-XIX вв. Авт. дис... канд. ист. наук. Саратов, 3.

3. Яковлева Л.Е. 2008. Развитие постойной повинности в России в XVIII-XIX вв. Дис... канд. ист. наук. Саратов, 126. 


\section{References}

1. Zayonchkovskiy P.A. 1952. Voennye reformy 1860-1870 gg. v Rossii [Military reforms of 1860-1870 in Russia]. Moscow, Izd-vo Moskovskogo un-ta, 46 (in Russian).

2. Yakovleva L.E. 2008. Razvitie postoynoy povinnosti v Rossii v XVIII-XIX vv. [Quarter Duty Development in Russia in XVIII-XIX Centuries]. Avt. dis... kand. ist. nauk. Saratov, 3 (in Russian).

3. Yakovleva L.E. 2008. Razvitie postoynoy povinnosti v Rossii v XVIII-XIX vv. [Quarter Duty Development in Russia in XVIII-XIX Centuries]. Dis... kand. ist. nauk. Saratov, 126 (in Russian).

\section{ИНФОРМАЦИЯ ОБ АВТОРЕ}

Орлов Андрей Сергеевич, кандидат исторических наук, сотрудник Академии Академия федеральной службы охраны Российской Федерации, г. Орел, Россия

\section{INFORMATION ABOUT THE AUTHOR}

Andrey S. Orlov, candidate of historical sciences, employee of the Academy of the Federal Security Service of the Russian Federation, Orel, Russia 